\title{
EVALUATING THE MADRASATI PLATFORM FOR THE VIRTUAL CLASSROOM IN SAUDI ARABIAN EDUCATION DURING THE TIME OF COVID-19 PANDEMIC
}

\author{
Badi Aldossryi \\ $\mathrm{PhD}$, Research Student, \\ University of Glasgow, \\ 11 Eldon St, Glasgow G3 6NH, \\ United Kingdom
}

\begin{abstract}
:
The platforms are the pinnacle of technology and digital development in the 21st century. However, until the global COVID-19 pandemic, most schools did not employ these platforms as new teaching and learning methods. The Ministry of Education in Saudi Arabia established the Madrasati Platform as the new gateway to distance-teaching and learning for all Saudi' education levels from $1^{\text {st }}$ to $12^{\text {th }}$ grade in the new academic year 2020-2021. This platform is one of the most essential programmes in Saudi Arabia, and is related to many supplemental educational tools. The data involved in this study was collected from three teachers. This paper presents the results of an evaluation of the Madrasati Platform in relation to Saudi teachers' perceptions of its use as the primary distance learning platform, and its advantages and disadvantages. The main findings are firstly that teachers should possess technical knowledge about how to use this platform, which highlighted the need for intense training courses for both teachers and students in order to create and foster a successful educational environment. The Madrasati Platform is an integrated platform designed to meet the needs of all of the parties involved. However, students typically neglect to attend the asynchronous virtual classroom on the platform (iEN channels and other uploaded videos) and focus only on the synchronously virtual (live) classroom on Teams. Therefore, this paper presents some recommendations to the Saudi Arabian education stakeholders for improved platform development, and also proposes paths for future research.
\end{abstract}

Keywords: Madrasati, platform, virtual-classroom, distance-learning, teacher' perception

i Correspondence: email badialdossry@gmail.com, b.aldossry.1@research.gla.ac.uk 


\section{Introduction}

Since February 2020, schools have initiated temporary closures due to the Coronavirus (COVID-19) which has affected students, teachers, and working parents alike (Nae, 2020). According to UNESCO monitoring (2020), more than 100 countries have implemented nationwide closures, which has negatively affected more than half of the world's student population. Undeniably, these closures have had significant negative impacts on students' educations (UNESCO, 2020). The Coronavirus (COVID-19) pandemic-related closures have caused substantial adoption of distance-learning across most educational institutions in a bid to halt the spread of the virus globally (Basilaia \& Kvavadze, 2020).

At the onset of COVID-19, Saudi Arabia (SA), like many countries globally, adopted distance-learning via virtual Classroom to ensure continued educational progress and as a precautionary measure to safeguard teachers and students from this disease. While some educational institutions have experience with distance-learning prior to COVID-19, this disease came suddenly for the majority. Thus, the Ministry of Education (MOE) in SA mandated the immediate application of distance-learning. According to Khanfar (2020), in the face of the rapid spread of COVID-19, educational institutions were left with no choice but to either postpone classes for an undetermined duration or immediately introduce online classes. Thus, the MOE created a virtual platform called the Madrasati Platform to function as a virtual classroom. As per Hegazy and Muhammad (2016), the virtual classroom is similar to the traditional classrooms in terms of the number of teachers and students, but it is accessed through the internet via a website or application. Subsequently, schools started to use educational platforms and their various tools to introduce the material and explain it in their virtual classrooms, and teachers could assess students through these platforms (Nae, 2020).

There are two types of virtual classroom, and both are dependent on the participants coming together and interacting and presenting online (Hegazy \& Muhammad, 2016). The first type of virtual classroom requires the teachers and learners to be present online with each other at the same time, connecting through instant chat or video conferences (Banani et al., 2020; Hegazy \& Muhammad, 2016). In contrast, the second type of virtual classroom does not require the learners to be online with each other or with their teacher at the same time. Thus, the learner can choose the most convenient or appropriate time based on their circumstances, effort, and ability to study the material by presenting the recorded sessions anytime and anywhere (Hegazy \& Muhammad, 2016).

As previously mentioned, the Madrasati Platform was created by the MOE to be a virtual classroom as a result of the decision by the Saudi government to close all public schools in the country. Initially, the plan was for schools to use the Madrasati Platform for the first seven weeks of the first semester of the 2020 educational year. Subsequently, the MOE announced that schools are to continue using this platform until further notice. According to Madrasati (2020), the Madrasati Platform is an e-learning system with many tools that support the learning and teaching process for all education levels from $1^{\text {st }}$ to 
$12^{\text {th }}$ grades. It also contributes to achieving the lessons plans and educational goals of the curriculum. Furthermore, it aids students in acquiring values, skills and new knowledge, and it is compatible with the digital requirements of the present and future (Madrasati, 2020). The Madrasati Platform features a package of educational tools to support the teaching and learning process. It is a virtual classroom that enables learners and their teachers to meet simultaneously via virtual meetings or at any convenient time for them through recorded lessons. In addition, it includes the Microsoft Office programme (365), which encompasses email service, teams, and a variety of channels for communication amongst students, teachers, or parents. It also provides visual videos, educational books and cartoons, and contains 45,000 digital educational contents and 450,000 electronic lesson plans. Moreover, it contains tools for educational planning and design which allows teachers to design lessons that consider the individual differences between learners. They can also create homework or electronic tests through this platform. Indeed, it has test-banks that contain in excess of 100,000 questions for measuring and evaluating educational and cognitive achievement. By the end of the first semester (17 weeks) of the year 2020, the Madrasati Platform had facilitated more than 89,000 virtual lessons for public and private schools in Saudi Arabia, and had 489 million visitors. Furthermore, 2.5 million electronic test forms were created by teachers and sent to students during the first semester, and students submitted more than 15 million items of homework and more than 10 million enquiries to teachers via this platform (MOE, 2020).

Khanfar (2020) investigated the most significant challenges encountered by female teachers in Eastern Region public schools in SA during the COVID-19 pandemic. She found that the most important challenges facing 375 female teachers from their perspective were the infrastructure and the skills required to use the Madrasati Platform. However, as discussed earlier, Madrasati has a variety of Microsoft Teams programs which provide safe virtual classes for students to interact with their teachers with regards to class e-activities and homework (Madrasati, 2020). They also received support and motivation from their teachers (Al-Zboun, 2020).

The use of distance-learning depends on the way in which a platform would be used for the teaching and learning processes. Research on distance-learning conducted by Khalife (2019) found that students' academic achievements in the treatment group were better than those of the control group. Despite recommending using modern techniques in learning and teaching methods, the study did not discuss how a platform for virtual classes was to be used for studying. While platforms differ from one to another, the majority rely on technical support services in order to successfully facilitate education. Khanfar (2020) asserts that technical support is essential to enhancing students' skill levels and enabling them to reap the most benefit from the various platform tools.

To the best of the researchers' knowledge, no studies focus on the Madrasati Platform in the context of teachers' perceptions related to the use of this platform as this study does, as this platform has just been adopted in Saudi's education system following the onset of COVID-19. This study will also cover the advantages and disadvantages of 
using this platform and examine means of further developing it. This study is focused on answering the following research questions:

1. What are the Saudi teachers' perceptions after using the Madrasati Platform as the primary distance-learning platform in Saudi Arabia?

2. What are the advantages and disadvantages of using the Madrasati Platform?

\section{Material and Methods}

In order to evaluate the Madrasati Platform for the virtual classroom, this study investigates the teachers' perceptions of its use, and its advantages and disadvantages. Furthermore, it makes several recommendations to develop this platform. The research approach used involved semi-structured interviews of teachers in secondary schools in Saudi Arabia. The sample was comprised of three teachers in secondary schools with one year of teaching experience using the Madrasati Platform since its emergence in Saudi's education system. The reason for this approach is that it enabled the researcher to collect the most relevant information directly from the respondents related to the research questions, while the qualitative data was supportive and helpful to understand the underlying of the research issue (Saunders et al., 2007). The collected data was documented in the written format and evaluated using thematic analysis. Thematic analysis facilitates the identification of specific patterns such as themes by pinpointing the essential information (Aldossry \& Lally, 2019).

\section{Results and Discussion}

The purpose of this research is to evaluate the performance of the Madrasati Platform in terms of functioning as a virtual classroom in SA during the COVID-19 pandemic. To address the research questions, qualitative data is collected from three teachers through interviews recorded for 10 to 15 minutes and analysed thematically in order to evaluate and understand the effectiveness of using the Madrasati Platform in Saudi's education. The findings of the teachers' semi-structured interview are presented below.

\subsection{Technical Knowledge}

The first theme of the interview analysis is technical knowledge about how to use the Madrasati Platform as a virtual classroom. According to the findings of the study, most of the teachers undertook a training course on using this platform during the first weeks of its introduction in the education system in Saudi Arabia. The teachers reported that there are many video clips that have been added online by the MOE or volunteer teachers since the platforms' integration which help to explain the issues that most of the teachers faced and give further instructions for its use.

Moreover, teachers mentioned that the platform is suitable for students in secondary schools because they have prior knowledge of the technology usage that has been acquired over time. In contrast, elementary school students have experienced 
difficulties in using the platform, as they have insufficient or no experience with how to use such technology. However, one of the teachers reported that students were not trained well to use the platform which impacts the learning process.

\subsection{The Role of the Teacher}

The role of the teacher in the education process has changed from the traditional role (teacher-centred approach) to a more extensive role. For example, a teacher is a conveyor of knowledge whilst also supporting students in the learning process. Technology is one of the tools supporting the teacher in this process. The Madrasati Platform facilitates teachers to teach the content in a virtual class that is similar to face-to-face teaching in most of the properties. Teachers reported that this platform has supplementary tools that help them to deliver the knowledge to their students, and they hope to continue using it even when schools reopen. For instance, one of the teachers suggests that this platform will reduce the role of the teacher, especially in theoretical materials, so that it will be better to continue teaching these materials online to save time and effort for teachers. However, he suggested also that the scientific material should be taught face-to-face, especially mathematics material. Once the COVID-19 pandemic has ended, continuing to use the Madrasati Platform will be beneficial as it will enable electronic correction to be applied to the majority of tests, homework, and assignments, thereby decreasing the time and effort required by teachers, and providing students with immediate results and feedback on their work.

However, teachers believe that the Madrasati Platform cannot replace the presence of the teacher in education due to the need for immediate in-person interaction between teachers and students.

\subsection{Virtual Classroom}

As mentioned above, there are two virtual classrooms: synchronously virtual (live) classroom and asynchronous virtual classroom (recorded). The findings reported that teaching through a synchronously virtual classroom using Microsoft Teams programme via the Madrasati Platform is the best distance-learning method for students to be with the teacher at the same time, as it encourages participation and interaction with the teacher to a far greater degree than recorded study or online self-study. Although an asynchronous virtual classroom depends entirely on students in their learning, it is characterized by flexibility in learning time, meaning that a student can study at any time they find convenient.

At the beginning of the pandemic, the MOE implemented the iEN channel as the asynchronous virtual classroom as a temporary solution until the Madrasati Platform was established. This iEN channel remains active and is used for the lessons through links connected with the platform to support the teacher to explain the lesson to students. It allows the teacher to provide extra explanations or upload a specific video that may be more helpful to the students' understanding of the lesson. Therefore, the educational process for both teachers and students can benefit from supplementary knowledge from 
a variety of sources such as the iEN channel or video clips that are accessible to students at any time.

\subsection{Unwillingness to Use the Madrasati Platform}

Despite an overall positive perception of the Madrasati platform, some teachers and students have described encountering many problems during the complicated registration process. Teachers reported that new users are required to initially register through another government programme (Tawakelna), which then requests a username and password from the central government programme (Abisheraccount). However, one of the teachers mentioned that school management had helped students and their families in the Platforms' registration process, and subsequently they did not have any issues with logging in daily, finding it to be convenient and easy.

Furthermore, teachers mentioned that the platform's design has many options that are not suitable for learning because it distracts students from the lessons' main goal. It is better to have a simple design for the platform to keep students attentive to the teacher and undistracted. Another reason for unwillingness to use this platform is that there is no video introduction on using this platform for students or teachers, which made it difficult to use.

No platform works very well without any issue. According to this study's findings, while there is an icon for IT service, it does not work when a user requests assistance to fix an issue. The issue could not be resolved through the IT service on the Platform, but it could be done when teachers and students requested a private IT service that cost them a fee. However, one of the teachers reported that the IT service is working well on the platform, which means that there is an IT service, but it does not cover all requests and take time to respond, which impacts the educational process.

\subsection{Advantages of the Madrasati Platform}

There are many advantages to the Madrasati Platform, but reaping their benefits necessitates teachers having strong skills, and students being capable of working themselves rather than relying on their teachers. The findings provide some of the advantages of the Madrasati platform, which are below:

- Integrated platform for all the needs,

- Provides electronic tests and assignments, which are easily corrected,

- Provides recorded lessons, video and voices,

- Straightforward to provide lessons,

- Does not require school attendance to present lessons,

- Builds learners' self-reliance,

- Flexibility of studying anytime and anywhere,

- Various sources of information and knowledge,

- Saves time and effort,

- Cost efficient,

- Saves the data of assignments, lessons, and tests in the service of the platform, 
- Preserves the environment by reducing traffic congestion.

\subsection{Disadvantages of the Madrasati Platform}

The Madrasati Platform has several disadvantages that negatively impact the teaching and learning processes. The findings provide some of disadvantages as follows:

- Students' fail to attend the asynchronous virtual classroom on the Platform and focus only on the synchronously virtual (live) classroom on Teams,

- Lack of students' attention compared to face-to-face education,

- Students not interacting as required,

- No direct connection on the platform except via supportive programmes such as Teams,

- Lack of control over the performance of some students during the virtual classroom,

- Unfair evaluation of outstanding students,

- Lack of flexibility in the sorting of students,

- Some technical problems, such as internet disruption and device availability issues for some families,

- Difficulty with log in or registration of new users,

- Interruptions to the Platforms' system.

However, some teachers proposed solutions to these disadvantages, such as intensifying the instructing students' roles and the presence of direct technical support for both teachers and students. In order to overcome these negatives, schools, teachers, and parents should cooperate with one another.

\subsection{The Preferred Device for Using the Madrasati Platform}

All teachers in this study preferred to use their personal computer (PC) while using the Madrasati Platform rather than other technology devices. They reported that the PC gives a better space and more flexibility for the teacher when using educational support programs and tools such as Word, PowerPoint, and others. Moreover, it enables the screen to be displayed and shared more clearly.

\subsection{Proposals for the Development of the Madrasati Platform}

The findings suggest proposals for stakeholders in the Saudi education system to develop the platform. According to the teachers, the most important development is in relation to IT, stating that the Platform must provide immediate technical support when any critical issue arises during teaching time. Additionally, it is essential that more intense training courses on how to use the Platform and its tool are offered to both teachers and students. Furthermore, it is better to integrate the Teams programme with the Platform to make the educational process more streamlined, and to connect the Platform with the Noor system so as to assess students directly. Thus, records of the attendance and absence of students on the Platform should be directly linked with the Teams program. Moreover, it should develop school schedules to be more flexible for the teacher, allowing them to 
be edited, and the schedule should always be displayed on the platform, as should activate notifications and messages, especially e-mail notifications.

In addition, the Platform should have a database for the scientific material, including homework and tests. For example, the Platform should have a tests-bank, especially for mathematics, as adding some tests' models would make it easier for the teacher to assess their students. It should also develop the tests-bank to be more flexible for editing and adding by the teacher, and in particular, allow them to add their tests to the tests-bank. Another point is that students should be aware that distance-learning could be successful based on their performance and interaction in the virtual classroom. Finally, one of the teachers suggested that the best educational method for science subjects is to study face-to-face at a school and continue distance-learning for theoretical materials.

\section{Recommendations}

The researcher recommends some areas for future studies:

- Further studies on the Madrasati Platform and collection of data from students and teachers,

- Further research about the effectiveness of the Microsoft Teams programme and students' achievements,

- Comparison of the synchronously virtual (live) classroom and asynchronous virtual classroom (recorded).

\section{Conclusion}

The research aimed to evaluate the Madrasati Platform for virtual classrooms in Saudi Arabian education. The data was collected from three teachers who had experienced one year using the Madrasati Platform in Saudi Arabia. The findings showed that technology knowledge for teachers and students is one of the most important elements to successful virtual classrooms. Teachers' knowledge of how to use technology is essential to achieving the lessons' goals, avoiding barriers to integrating technology in education, and being ready for future changes to teaching and learning methods (Koehler \& Mishra, 2009). Therefore, teachers should be knowledgeable about using the Madrasati Platform in order to take full advantage of the benefits it offers, and to effectively convey lessons to their students. Teachers in this study suggest that the platform will reduce the teachers' role in future, especially in theoretical materials, and hope to continue teaching these materials using this platform even after the COVID-19 pandemic has ended. Still, they remain convinced that the scientific material should be taught by attending school and learning face-to-face.

The Madrasati Platform has two kinds of virtual classrooms which are synchronously virtual classroom (live, using Microsoft Teams programme) and asynchronous virtual classroom (recorded, using iEN channels). Teachers preferred to 
use the synchronously virtual classroom because they can interact with their students at the same time. Yet, the asynchronous virtual classroom has more flexibility in terms of time to teach and learn. However, the teachers also reported that due to the complicated registration process, some teachers and students were hesitant to use the Platform when it was first introduced. In addition, there is no video introduction for using this platform for students or teachers, which made it difficult to use, and there was no instantaneous IT service. The study suggests that reducing the security requirement for new registration or recovery of the password and a video introduction on how to use it step by step with an IT service that responds immediately would be very valuable.

The Madrasati Platform has many advantages such as an integrated platform, ease in providing lessons, electronic tests and assignments, distance-learning, it builds learners' self-reliance, saves data, time, effort, and financial waste, and reduces traffic congestion. However, the Madrasati Platform also has several negative aspects, including a decrease in students' attention levels and lack of flexibility in sorting them, less interaction, and no direct connection between teacher and student. Additionally, there is unfair evaluation of outstanding students, and they did not prefer attending the asynchronous virtual classroom (iEN channels or other recorded video) and only focused on synchronously virtual (live) classroom on Teams. Moreover, there are some technical problems and issues with the suspension of the Platforms' system.

Finally, the teachers expressed that they preferred using their personal computers (PC) over other technology devices to access this Platform because of better space and more flexibility to use supportive tools such as Word, PowerPoint, and others. The study has proposed some suggestions to the stakeholders in Saudi education to develop the platform, such as offering immediate technical support for any emergency issue, offering a database, and intensifying training courses for teachers and students. Furthermore, it is preferable to integrate the Teams programme and NOOR system with the Madrasati Platform, and to activate notifications and messages, especially e-mail notifications. Another recommendation is that the Platform should allow for more flexibility for teachers in terms of editing and amending schedules.. The school schedule should always be displayed on the Platform and linked to the attendance and absence records between the NOOR system, the Madrasati Platform and Teams programme.

\section{Conflict of Interest Statement}

The author declares no conflicts of interests.

\section{About the Author}

Badi is a PhD researcher at the School of Education, University of Glasgow, UK. He has also been the director of the Saudi Society (GUSS) at the university since 2019. His study is focused on E-Learning in mathematics education, and he has experience teaching mathematics since 2007. 


\section{References}

Aldossry, B., and Lally, V. (2019). Investigating The Integration Of iPad Among Mathematics Teachers In A Secondary School In Saudi Arabia Based On TPACK Model, Edulearn19 Proceedings, Pp. 8133-8138.

Basilaia, G., \& Kvavadze, D. (2020). Transition to Online Education in Schools during a SARS-CoV-2 Coronavirus (COVID-19) Pandemic in Georgia. Pedagogical Research, 5(4), 2-9.

Hegazy, I. A., and Muhammad, S. H. S. (2016). Blackboard Collaborate Quality Standards for faculty members at King Saud University. Researches of the Sixth Arab International Conference on Higher Education Quality Assurance LACQA 2016: Sudan University of Science and Technology and Zarqa University of Jordan, Khartoum: Sudan University of Science and Technology, 351-364.

Khalife, W. (2019). The effectiveness of using active learning based on distance learning on improving academic achievement and developing the trend towards distance learning for the learning technologies course for mathematics education students. The Scientific Journal of Physical Education and Sports Sciences, 87(2), 321- 334.

Khanfar, A. R. (2020). Distance-learning entrepreneurship education in the time of corona virus - COVID-19 challenges \& solution. Journal of Entrepreneurship Education, 23(S1).

Koehler, M. and Mishra, P. (2009). What is technological pedagogical content knowledge (TPACK)?. Contemporary issues in technology and teacher education, 9(1), pp.6070.

Madrasati. (2020). Ministry of Education, Kingdom of Saudi Arabia. Retrieved from: https://backtoschool.sa/ (accessed on 19/02/2021).

MOE (2020). Ministry of Education, Kingdom of Saudi Arabia. Retrieved from https://www.moe.gov.sa/ar/mediacenter/MOEnews/Pages/MR2-2020-453.aspx (accessed on 21/02/2021).

Nae, N. (2020). Online learning during the pandemic: where does Japan stand? Euromentor Journal, 11(2), 7-24. Retrieved from: https://www.researchgate.net/publication/342505298 ONLINE LEARNING DU RING THE PANDEMIC WHERE DOES JAPAN STAND (accessed on 18/02/2021).

Saunders, M., Lewis, P., and Thornhill, A. (2007). Research methods. Business Students 4 th edition Pearson Education Limited, England.

UNESCO (2020). UNESCO Report, COVID-19 Educational Disruption and Response. Retrieved from https://en.unesco.org/news/covid-19-educational-disruption-andresponse (accessed on 18/02/2021). 
Badi Aldossry

EVALUATING THE MADRASATI PLATFORM FOR THE VIRTUAL CLASSROOM

IN SAUDI ARABIAN EDUCATION DURING THE TIME OF COVID-19 PANDEMIC

Creative Commons licensing terms

Authors will retain the copyright of their published articles agreeing that a Creative Commons Attribution 4.0 International License (CC BY 4.0) terms will be applied to their work. Under the terms of this license, no permission is required from the author(s) or publisher for members of the community to copy, distribute, transmit or adapt the article content, providing a proper, prominent and unambiguous attribution to the authors in a manner that makes clear that the materials are being reused under permission of a Creative Commons License. Views, opinions and conclusions expressed in this research article are views, opinions and conclusions of the author(s). Open Access Publishing Group and European Journal of Open Education andE-learning Studies shall not be responsible or answerable for any loss, damage or liability caused in relation to/arising out of conflict of interests, copyright violations and inappropriate or inaccurate use of any kind content related or integrated on the research work. All the published works are meeting the Open Access Publishing requirements and can be freely accessed, shared, modified, distributed and used in educational, commercial and non-commercial purposes under a Creative Commons Attribution 4.0 International License (CC BY 4.0). 